OPEN ACCESS

Edited by:

Massimo Valoti,

University of Siena, Italy

Reviewed by:

Risto Olavi Juvonen,

University of Eastern Finland, Finland

Guang-Bo Ge,

Shanghai University of Traditional

Chinese Medicine, China

*Correspondence:

Guangji Wang

gjwcpu@163.com

Ying Zhou

zyyiva@163.com

${ }^{\dagger}$ These authors have contributed equally to this work and share first

authorship

Specialty section:

This article was submitted to Drug Metabolism and Transport, a section of the journal

Frontiers in Pharmacology

Received: 17 October 2021 Accepted: 22 November 2021 Published: 15 December 2021

Citation:

Liu Z, Wen X, Wang G and Zhou Y (2021) Involvement of $P$-gp on Reversing Multidrug Resistance Effects of 23-Hydroxybetulinic Acid on

Chemotherapeutic Agents. Front. Pharmacol. 12:796745. doi: 10.3389/fphar.2021.796745

\section{Involvement of P-gp on Reversing Multidrug Resistance Effects of 23-Hydroxybetulinic Acid on Chemotherapeutic Agents}

\author{
Zhihao Liu ${ }^{1,2 \dagger}$, Xiaozhou Wen ${ }^{3,4,5 t}$, Guangji Wang ${ }^{3 *}$ and Ying Zhou ${ }^{1,3 *}$ \\ ${ }^{1}$ Department of Pharmacy, The First Affiliated Hospital of Nanchang University, Nanchang, China, ${ }^{2}$ Department of Clinical \\ Pharmacology, College of Pharmacy, Dalian Medical University, Dalian, China, ${ }^{3}$ Key Laboratory of Drug Metabolism and \\ Pharmacokinetics, China Pharmaceutical University, Nanjing, China, ${ }^{4}$ Jiangsu Province Hospital of Chinese Medicine, Nanjing, \\ China, ${ }^{5}$ Affiliated Hospital of Nanjing University of Chinese Medicine, Nanjing, China
}

Betulinic acid (BA) and 23-Hydroxybetulinic acid (23-HBA) are natural products with similar structures, which show a range of biological effects including cytotoxicity activity. The aim of current research was to investigate and evaluate the combinational cytotoxicity of BA and 23-HBA with chemotherapeutic agents in vitro, and to clarify the potential interaction and related mechanism with P-gp. Instead of BA, 23-HBA could increase cytotoxicity of MCF-7/ ADR cells to adriamaycin (ADR) and vincristine (VCR). The intracellular accumulation of ADR/ VCR in MCF-7/ADR cells was obviously increased in the presence of 23-HBA. Furthermore, 23-HBA could show dose-dependent increase on the transport of VCR and digoxin, which are typical P-gp substrates, in both MDCK-MDR1 and Caco-2 cells. However, the transport of BA and 23-HBA was not influenced by P-gp inhibition in MDCK-MDR1 cells. MDR1 shift assay and molecular docking model suggested that both compounds showed interaction with P-gp, yet the binding affinity and sites are different. In conclusion, 23-HBA could strongly improve the efficacy of anti-tumor agents in multidrug resistance (MDR) cells, which was related to P-gp inhibition. The MDR1 shift assay and molecular docking study further revealed that 23-HBA and BA showed different interaction modes with P-gp.

Keywords: betulinic acid, multidrug resistance, P-gp, 23-hydroxybetulinic acid, cytotoxicity

\section{INTRODUCTION}

The incident of malignant tumors is a frequent disease which widely threatens human health, and the death rate of tumors is second in all diseases, exceeded only by heart disease (Masoudkabir et al., 2017). Until now, special effective treatments for tumors haven't be found, and chemotherapy is still an effective and widely used approach for curing malignant tumors (Zarros et al., 2018). However, during the long-term applications, chemotherapeutics include side effects and the emergence of drug resistance (Maino et al., 2000; Alfarouk et al., 2015). It is an urgent to search for novel antitumor drugs or ancillary drugs for pharmaceutical researchers.

Multidrug resistance (MDR) could lead to low efficiency of chemotherapeutic agents that are mechanistically and/or structurally unrelated and therefore strongly cause treatment effects of drugs (Xue et al., 2016; Sun et al., 2019). The mechanisms of MDR are various, yet, the most acceptable reason would be the high expression of ATP-binding cassette (ABC) transporters (Nanayakkara et al., 2018). P-glycoprotein (P-gp) is one of the most investigated ATP-dependent transmembrane 
transporters (Li et al., 2014). Besides its role in cancer cell resistance, P-gp has multiple physiological functions as well, since it's expressed also in many important non-tumoural tissues (Zhang et al., 2018). It was suggested that in tumors, P-gp are expressed not only in cell membranes but also in membranes of some subcellular organelles (such as mitochondria and nucleolus) (Munteanu et al., 2006). These organelles are target points of most antineoplastic. P-gp, which is overexpressed in tumor cells, could increase the excretion, reduce the concentration of chemotherapeutic agents in target cells and organelles, and finally generate drug resistance (Wang et al., 2016). Considering the key role of P-gp in MDR, developing P-gp inhibitors is of great clinical significance, since it could reduce dosage of antineoplastic and raise curative effect (Jia et al., 2016). Natural products and their derivatives with P-gp inhibitory property have been paid more and more attention in recent years, such as glycyrrhitic acid, emodin, and ginsenoside (Li et al., 2014; Alfarouk et al., 2015), which show potency and multitarget compared with traditional P-gp inhibitors (Dewanjee et al., 2017).

Betulinic acid (BA) was first isolated from the East African evergreen tree, Ziziphus mauritiana (Fong et al., 1995). It is a naturally occurring pentacyclic triterpenoid, which has revealed cytotoxicity effects against some specific tumors (like melanoma, head and neck squamous cell carcinoma, etc.) (Fulda, 2008; Saeed et al., 2018). Previous reports suggested that, besides inducing apoptosis, it could also act as a chemosensitizer and radiosensitizer in some tumors (Fulda and Kroemer, 2009). The mechanism is not clear; furthermore, whether it's relevant to some transporters (such as P-gp) hasn't been reported yet. One type of opentacyclic triterpenes, 23-hydroxybetulinic acid (23-HBA), is an analogue of BA (Zhou et al., 2019). It's the important active component of Pulsatilla chinensis (Bunge) Regel, which shows "blood-cooling" and detoxification activities. And, 23-HBA has been reported to express cytotoxicity against various tumors and HIV and could restrain vascularization. In the previous study, it was confirmed that 23-HBA could enhance the cytotoxicity of cancer cells to current antitumor agents, which was associated with regulating P-gp expression and function (Zheng et al., 2010).

However, still unknown is the mechanism of $\mathrm{P}$-gp on reversing MDR effects by 23-HBA on chemotherapeutic agents and whether 23-HBA and BA perform similar mechanism of reversing MDR. This will be the goal concerned in the present research. Firstly, we studied the inversion effect of MDR by noncytotoxic BA and 23-HBA in MCF-7 and MCF-7/ADR cells; then, we compared P-gp inhibition activities of 23-HBA and BA by using Caco-2 cells and MDCK-MDR1 cells, which are both "golden models" to investigate P-gp mediated drug disposition (Sun and Pang, 2008; Liu and Liu, 2016); in the last, we studied the structure-activity relationship of BA and 23HBA with P-gp by MDR1 shift assay, molecular docking, and MDCK-MDR1 monolayers.

\section{MATERIALS AND METHODS}

\section{Chemicals}

Betulinic acid (BA, purity $\geq 98 \%$ ) was obtained from Shanghai Ronghe Medicine Science and Technology Co., Ltd. (China). In addition, 23-hydroxybetulinic acid (23-HBA, purity $\geq 99.8 \%$ ) was obtained from Professor Wencai Ye at Jinan University. Verapamil hydrochloride was obtained from the National Institute for the Control of Pharmaceutical and Biological Products (China). Adriamycin (ADR) was obtained from Zhejiang Hisun Pharmaceutical Co., Ltd. (China). Vincristine (VCR) was purchased from Hangzhou Minsheng Pharmaceutical Group Co., Ltd. (China). All other solvents and reagents were of analytical grade.

\section{Cell Cultures}

MCF-7 (human breast carcinoma cells) and MCF-7/ADR (P-gpoverexpressing derivative cells) cell lines were obtained from Blood Diseases Hospital, Chinese Academy of Medica (Shi et al., 2011). The cells were routinely maintained in RPMI 1640 with $10 \%$ heat-inactivated fetal bovine serum (FBS), 1\% non-essential amino acid solution, $0.1 \mathrm{mg} / \mathrm{ml}$ streptomycin, and 100 units $/ \mathrm{ml}$ penicillin. Caco-2 cells were purchased from American Type Culture Collection (ATCC, Rockville, MD, United States). Vector-MDCK and MDR1-MDCK cells were purchased from PharmaResources Co., Ltd. (China). Both Caco-2 and MDCK cells were maintained at Dulbecco's modified Eagle's medium (DMEM) with 10\% FBS, $1 \%$ nonessential amino acid solution, $0.1 \mathrm{mg} / \mathrm{ml}$ streptomycin, and 100 units/ml penicillin. MCF-7/ADR cells were treated with $2 \mathrm{mg} / \mathrm{ml} \mathrm{ADR}(2 \mathrm{mg} / \mathrm{ml})$ and were cultured in ADR-free medium for more than 14 days before the experiment. All cells were cultured at $37^{\circ} \mathrm{C}$ in a humidified atmosphere of $5 \% \mathrm{CO}_{2}$.

\section{Trypan Blue Exclusion Assay}

Trypan blue exclusion assay was used to measure the viability of cells to compounds. Briefly, MCF-7/sensitive (MCF-7/S) and MCF-7/ADR cells were diluted into the density of $0.5 \times 10^{4}$ cells $/ \mathrm{ml}$, then cells $(1 \mathrm{ml})$ were seeded in culture plates. After $24 \mathrm{~h}$, cells were given $\mathrm{ADR}(0.08 \mu \mathrm{M}$ for $\mathrm{MCF} / \mathrm{S}$, $3 \mu \mathrm{M}$ for $\mathrm{MCF} / \mathrm{ADR})$ or $\mathrm{VCR}(0.5 \mu \mathrm{M}$ for $\mathrm{MCF} / \mathrm{S}, 6 \mu \mathrm{M}$ for $\mathrm{MCF} /$ $\mathrm{ADR}$ ) alone, or in combination with series concentrations of $\mathrm{BA}$ or 23 -HBA $(0.2,2$ and $20 \mu \mathrm{M})$, and were cultured at $37^{\circ} \mathrm{C}$ for $48 \mathrm{~h}$. The cells were exposed to trypan blue assay (Gibco, Carlsbad, CA, United States) in a ratio of 1:9. The viable and dead cells (stained in blue) were counted by haemacytometer.

\section{Hoechst Assay}

MCF-7/ADR cells were collected and cultured at the density of $2.0 \times 10^{5} /$ well in 24 -well plates. Then the cells were exposed to $\operatorname{ADR}(3 \mu \mathrm{M})$ without or with BA/23-HBA $(0.2,2$, and $20 \mu \mathrm{M})$. The cells were dyed with Hoechst 33,342 (Beyotime, Shanghai, China) in the dark at $37^{\circ} \mathrm{C}$ for $30 \mathrm{~min}$ after washing with phosphate buffered saline (PBS). The morphological changes of the nucleus were evaluated by a fluorescence microscope.

\section{Adriamycin/Vincristine Accumulation Study} MCF-7 cells $\left(1 \times 10^{5} / \mathrm{Well}\right)$ were incubated in 24 -well plates. Then, for both ADR and VCR groups, the cells were given ADR/VCR $(5 \mu \mathrm{M})$ without or with verapamil $(20 \mu \mathrm{M})$ or BA/23-HBA $(0.2,2$, and $20 \mu \mathrm{M})$. After $1 \mathrm{~h}$ incubation, the compound solution was 


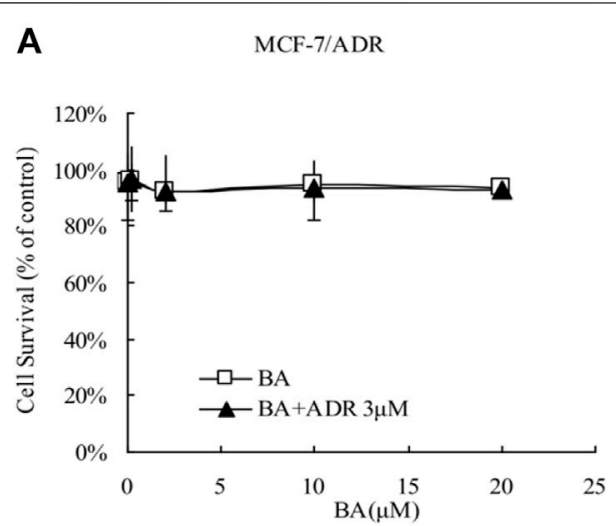

C

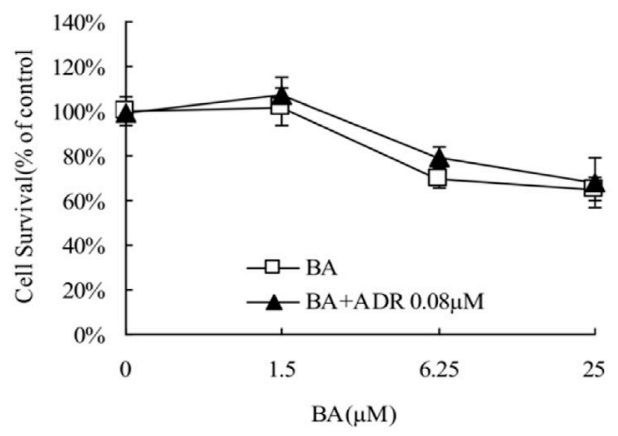

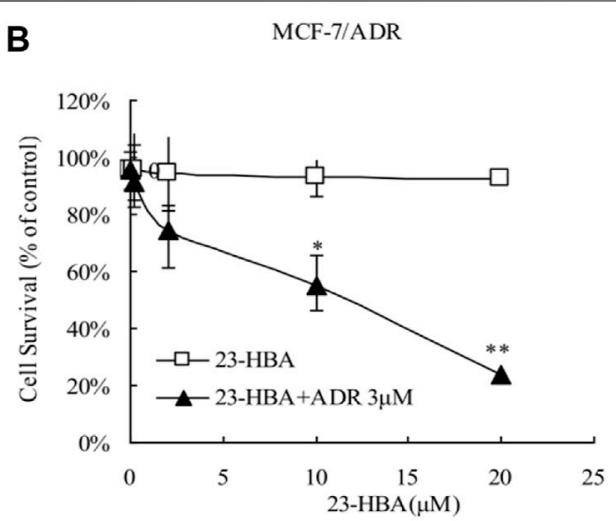

D

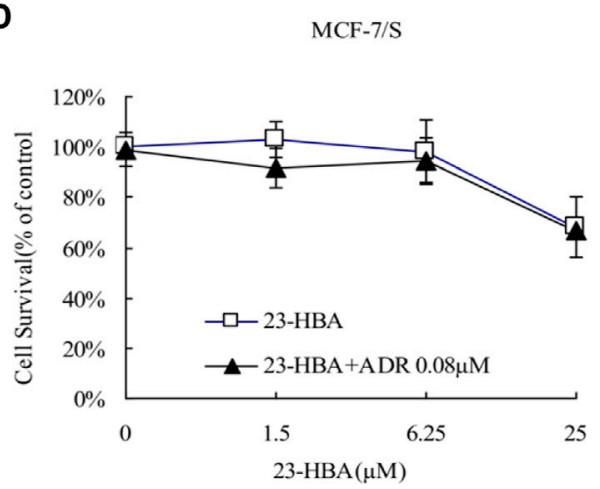

FIGURE 1 | Effects of 23-HBA and BA on the cell survival of MCF-7/ADR (A and B) and MCF-7/S (C and $\mathbf{D})$ cells to ADR. The cells were incubated for 48 h with ADR in the absence or presence of three different concentrations of 23-HBA (or BA), and cell growth inhibition was determined by Trypan Blue counting assays. ${ }^{\star} p<0.05$, ${ }^{\star \star} p<0.01,{ }^{\star \star \star} p<0.001$ vs. control.

aspirated to stop further accumulation, and the monolayers were rinsed with cold Hank's solution for three times. The drug content was detected by lysing the cells with ultrasound, and then the single well lysate was transferred to a plastic EP tube for further analysis. The protein concentration of the cells was measured using Coomassie brilliant blue.

\section{Caco-2 Uptake Study}

The Caco-2 cells uptake study was taken as described previously with minor modifications (Liu et al., 2011). Briefly, the cells $\left(1 \times 10^{5} /\right.$ Well $)$ were cultured in 24 -well plates, and culture medium was changed every other day. The uptake study was taken when the monolayers formed. For digoxin groups, the cells were given digoxin $(5 \mu \mathrm{M})$ with or without verapamil $(20 \mu \mathrm{M})$ or BA/23-HBA $(0.2,2$, and $20 \mu \mathrm{M})$. For vincristine groups, the cells were given VCR $(2 \mu \mathrm{M})$ with or without verapamil $(20 \mu \mathrm{M})$ or BA/23-HBA $(0.2,2$, and $20 \mu \mathrm{M})$. After $2 \mathrm{~h}$ incubation, the drug solution was removed to terminate reaction, and the monolayers were washed three times with cold Hank's solution. The other steps were taken according to the above process in Adriamycin/ Vincristine Accumulation Study.

\section{MDCK-MDR1 Transport Study}

The MDCK-MDR1 cells transport study was taken as described previously with minor modifications (Liu et al., 2016). Briefly,
MDCK-MDR1 cells $\left(1 \times 10^{5} /\right.$ Well $)$ were seeded onto $0.4 \mathrm{~mm}$ pore-size transwell inserts (Millipore, MA, United States) in 24-well plates. Cells were cultured for 5-7 days, when the transepithelial electrical resistance (TEER) values were $120-240 \Omega \mathrm{cm}^{2}$.

Firstly, transport study was taken to determine the inhibition effects of the BA/23-HBA on P-gp. The cells were rinsed with warmed Hank's balanced salt solution (HBSS), and the inserts were incubated for $20 \mathrm{~min}$ at $37^{\circ} \mathrm{C}$. Then the transport was started by adding HBSS containing known P-gp substrate digoxin $(5 \mu \mathrm{M})$ with or without BA/23-HBA $(0.2-20 \mu \mathrm{M})$ to either apical or basolateral side of monolayer. Aliquots $(50 \mu \mathrm{l})$ were taken from the receiver compartment at intervals of $30,60,90$, and $120 \mathrm{~min}$ and replaced with fresh buffer. In the study, verapamil (VER), known P-gp inhibitor, was selected as positive control. Secondly, the transport study was taken to certify whether BA/23HBA are substrates of P-gp. The study was initiated by adding HBSS containing BA/23-HBA $(0.2-20 \mu \mathrm{M})$ with or without verapamil $(20 \mu \mathrm{M})$ to either apical (A) or basolateral (B) side of monolayer. The other steps were taken according to the above process.

\section{MDR1 Shift Study}

The MDR1 shift assay was taken according to the manufacturer's protocol (Millipore Bioscience Research Reagents, Temecula, 

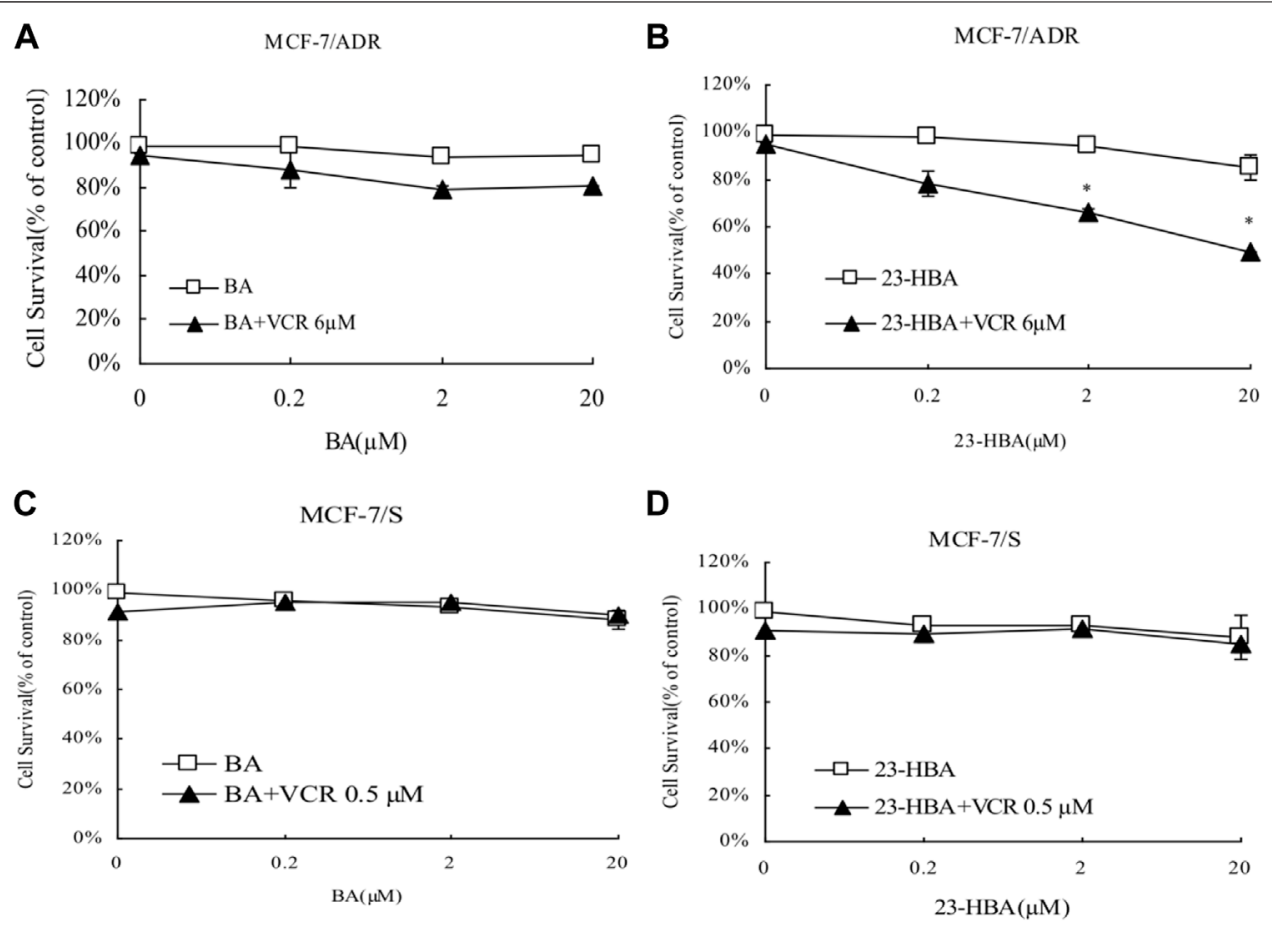

FIGURE 2 | Effects of 23-HBA and BA on the cell survival of MCF-7/ADR (A and B) and MCF-7/S (C and $\mathbf{D})$ to VCR. Cells were treated for $48 \mathrm{~h}$ with VCR and three different concentrations of $23-\mathrm{HBA}$ (or BA), and cell growth inhibition was detected by Trypan Blue counting assays. ${ }^{\star} p<0.05,{ }^{* \star} p<0.01,{ }^{* \star *} p<0.001$ vs. control.

CA) and previous report (Zhang et al., 2010). Briefly, MCF-7/ADR cells $\left(1 \times 10^{6}\right.$ cells $\left./ \mathrm{ml}\right)$ were collected and exposed in UIC2 binding buffer followed by pre-incubated at $37^{\circ} \mathrm{C}$ for $10 \mathrm{~min}$, then reaction was started by adding BA/23-HBA $(25 \mu \mathrm{M})$ at $37^{\circ} \mathrm{C}$ for another $10 \mathrm{~min}$. The monoclonal antibody UIC2 $(2.5 \mu \mathrm{l})$ was added and incubated for $15 \mathrm{~min}$, then $1 \mathrm{ml}$ of cold binding buffer was used to terminate reaction. The cells were rinsed twice, followed by adding cold phycoerythrin-labeled anti-mouse IgG $(250 \mu \mathrm{l})$ for another $15 \mathrm{~min}$ in the dark. Finally, cells were rinsed and incubated in cold binding buffer $(250 \mu \mathrm{l})$ and further evaluated by flow cytometer (Cytomics FC 500; Beckman Coulter, Fullerton, CA). In this study, vincristine $(25 \mu \mathrm{M})$ was set as positive control.

\section{Molecular Docking Study}

The binding mechanisms of BA/23-HBA with P-gp were evaluated by molecular docking approach with AutoDock 4.2 in Sybyl version. The crystal structure of MDR1A/P-gp (PDB code: 3G60) was selected in the docking approach (Liu et al., 2016). In the processing, all the ligand residues were permitted to shift while the structure of P-gp protein was fixed. The conformations with lowest binding energy were chosen for further mechanism evaluation.

\section{Analysis Method}

See supporting information Supplementary Material S1.

\section{Data Analysis}

The apparent permeability values $\left(\mathrm{P}_{\mathrm{app}}\right)$ were evaluated in all experiments according to the following equation:

$$
P_{a p p}=\frac{d Q / d t}{A C_{0}}
$$

where $A$ means the insert area and $C_{0}$ represents the initial concentration. $\mathrm{dQ} / \mathrm{dt}$ represents the slope of the cumulative content transported during the time course of the period studied.

The efflux ratio (ER) was detected according to the ratio of $\mathrm{P}_{\text {app }}$ as the following equation:

$$
\mathrm{ER}=\frac{P_{a p p}(B-A)}{P_{a p p}(A-B)}
$$

The individual point was expressed by mean \pm S. D unless indicated otherwise. The statistical analysis between different groups was performed by non-paired $t$-test. Values with $p<0.05$ were considered as statistically significant.

\section{RESULTS}

\section{Effects of BA/23-HBA on Potentiating Cytotoxicity of MCF-7 Cells to ADR or VCR} Instead of BA, 23-HBA can increase cytotoxicity of MCF-7/ADR cells to ADR or VCR in concentration-dependent manner (Figures 1A,B, Figures 2A,B). However, for MCF-7/S cells, neither 23-HBA nor BA showed significant effects on cytotoxicity in MCF-7/S cells (Figures 1C,D, Figures 2C,D).

In addition, Hoechst assay was further used to detect effects of the combination exposure on the apoptosis of MCF-7/ADR cell line. The number of apoptosis cells in BA $(20 \mu \mathrm{M}), 23-\mathrm{HBA}$ 

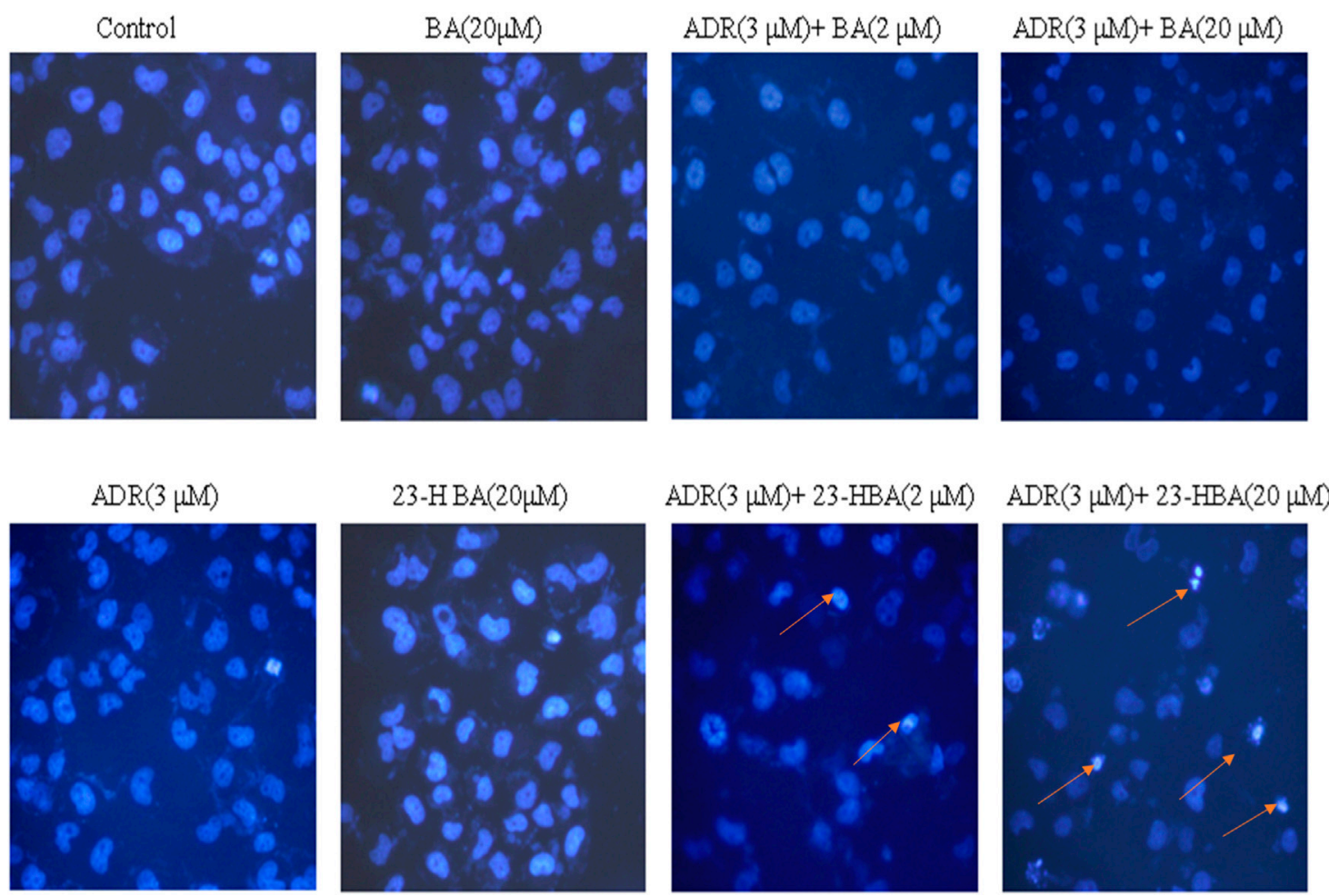

FIGURE 3 | Fluorescence intensity of ADR $(3 \mu \mathrm{M})$ in the presence or absence of different concentrations of 23-HBA and BA ( 2 and $20 \mu \mathrm{M})$ in MCF-7/ADR cell. Cells were treated with $3 \mu \mathrm{M}$ of ADR and 23-HBA (2 and $20 \mu \mathrm{M})$ for $2 \mathrm{~h}$. Then cells were fixed with $4 \%$ formaldehyde. After staining with Hoechst 33,342 , the fluorescence intensity of ADR was determined by high content analysis $(200 \times)$. Arrowheads indicate the apoptosis cells.

$(20 \mu \mathrm{M})$, or ADR $(3 \mu \mathrm{M})$ group was not obviously different with the control group (Figure 3). However, in 23-HBA combination exposure group, 23-HBA could produce a dose-dependent (2 and $20 \mu \mathrm{M})$ increase in the apoptosis caused by $\operatorname{ADR}(3 \mu \mathrm{M})$. All results suggested that the combination exposure of 23-HBA revealed a stronger effect on increasing the cytotoxicity of resistant cells to ADR or VCR.

\section{Effects of BA/23-HBA on the Uptake of ADR/VCR in MCF-7 Cells}

To understand the mechanism and cytotoxicity difference between $\mathrm{BA}$ and 23-HBA, the accumulation of ADR/VCR with or without BA/23-HBA was measured in MCF-7 cells. The results confirmed that accumulation amouts of ADR/VCR in MCF-7/S cells were greater than that of MCF-7/ADR cells (Figures 4A,C). In addition, instead of BA, intracellular accumulation of ADR/VCR was obviously increased in the presence of 23-HBA in resistant MCF-7 cells, which was similar with typical P-gp inhibitor verapamil (Figures 4A,C). However, little impact was observed on the accumulation of ADR/VCR in the sensitive MCF-7 cells with or without BA/ 23-HBA (Figures 4B,D). In summary, these results suggested that 23-HBA would inhibit P-gp-involved accumulation in resistant MCF-7 cells.

\section{Effects of BA/23-HBA on the Activity of P-gp in Caco-2 Cells}

To elucidate the interaction of $\mathrm{BA} / 23-\mathrm{HBA}$ on the function of $\mathrm{P}$-gp, the uptake of VCR was measured in Caco-2 cells. Also, 23HBA $(0.2,2$, and $20 \mu \mathrm{M})$ showed dose-dependent increase on the penetration of VCR and digoxin (Figure 5), which were known substrates of P-pg. In addition, the inhibitory effect of 23-HBA $(20 \mu \mathrm{M})$ was higher than that of verapamil $(20 \mu \mathrm{M})$, which was a typical inhibitor of P-gp. However, almost no obvious inhibition was observed for $\mathrm{BA}$ at different concentrations. The results suggested that 23-HBA, instead of $\mathrm{BA}$, could be a potential inhibitor of P-gp.

\section{Interaction Between BA/23-HBA and P-gp Across MDCK-MDR1 Cell Monolayers}

To further confirm the interaction between BA/23-HBA and P-gp, the transcellular transport study was performed in MDCK-MDR1 cell model. The transports of digoxin from basal (B) to apical (A) were greater than those from apical (A) to basal (B) for all three concentrations used in MDCK-MDR1 cells, and this direction could be partly reversed when 23-HBA was in combination (Table 1). The results suggested that the model is successful and further confirmed that 23-HBA, instead of BA, was a potential inhibitor of P-gp. As expected, 23-HBA 


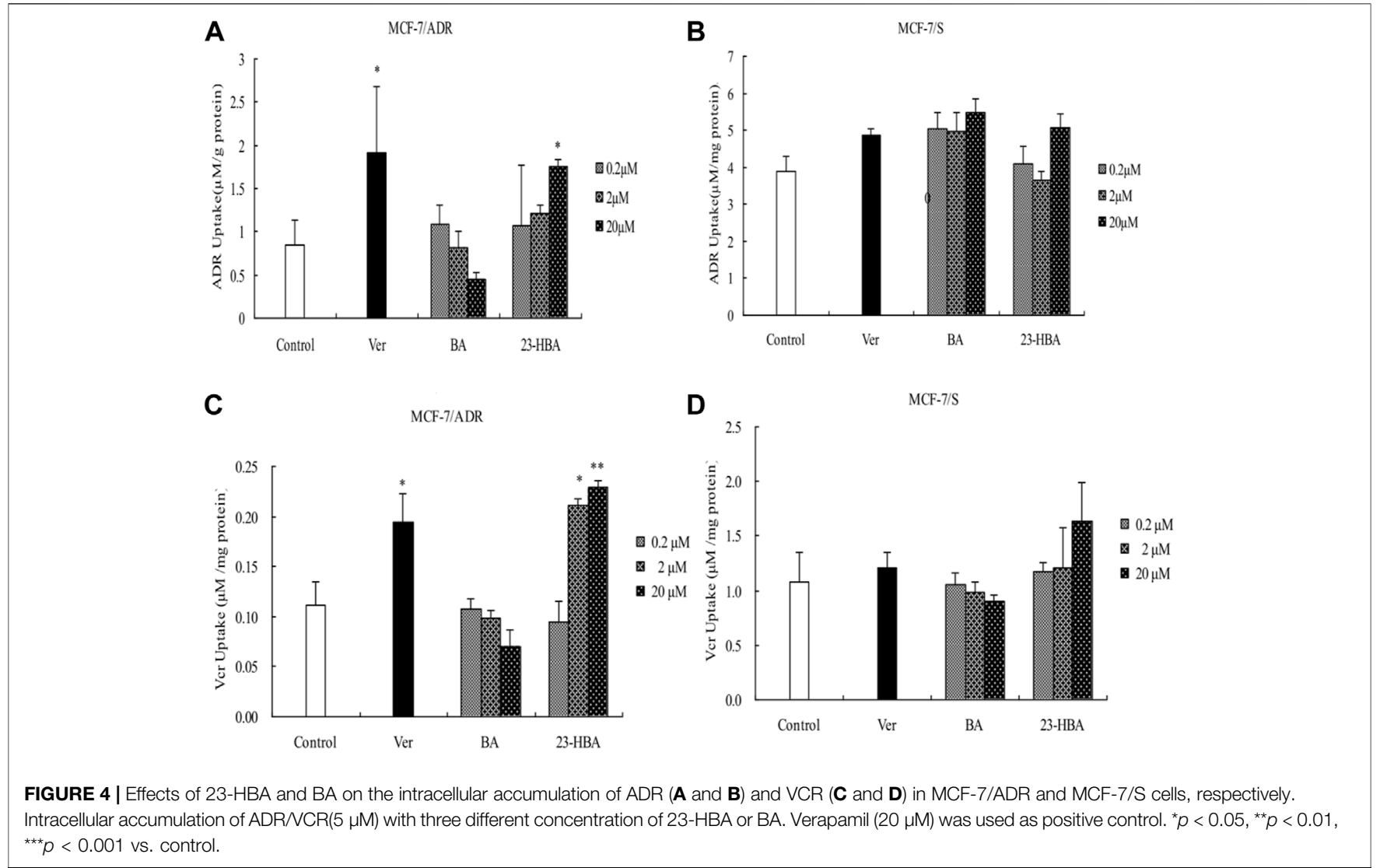

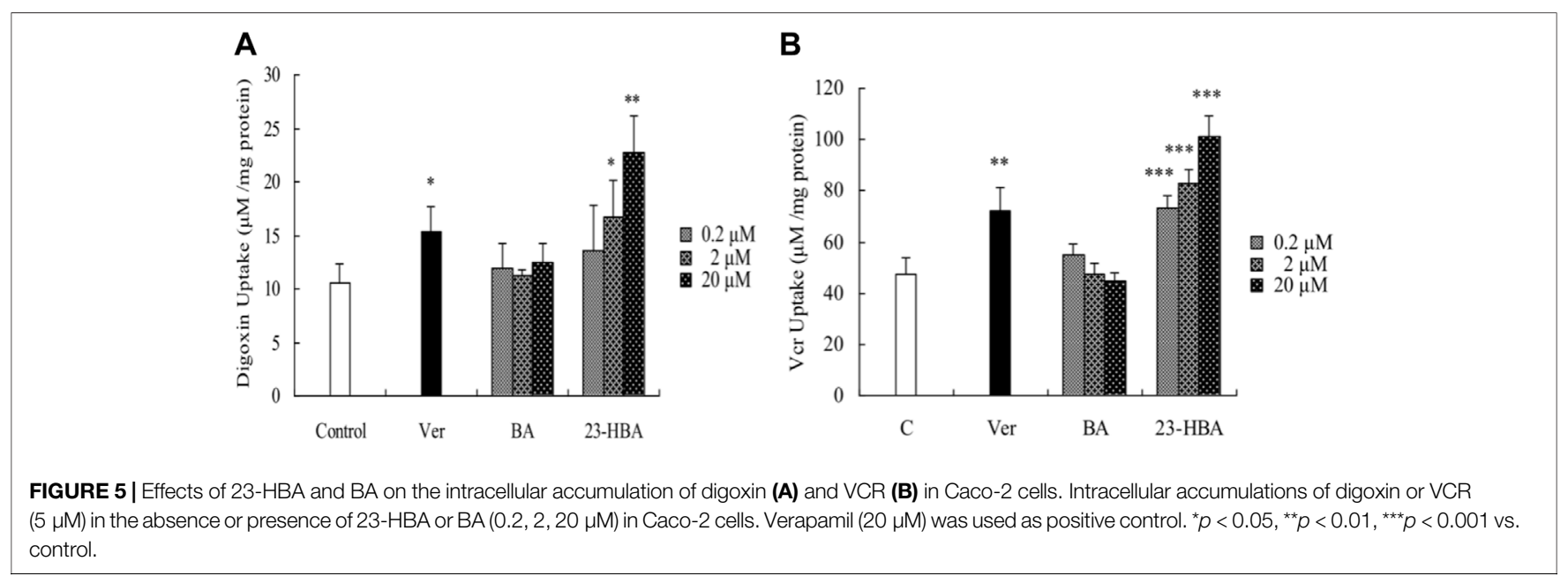

could dose-dependent increase the penetration (A-B) and decrease efflux (B-A) of VCR, and thus reversed the transport direction represented by efflux ratio (ER) values (Table 2 ). The results suggested that the 23-HBA would inhibit the activity of $\mathrm{P}$-gp and then influence the polar transport of VCR. In addition, further study was taken to verify whether BA and 23-HBA were substrates of P-gp in MDCK-MDR1 cells. The ER values for both $\mathrm{BA}$ and 23-HBA were less than 1.5 at all the concentrations; however, verapamil could partly influence the penetration and efflux (Table 3 ). The results suggested that P-gp could slightly influence the transport of BA and 23-HBA, yet the impact was limited. 
TABLE 1 | Apparent permeability coefficient (Papp) and net efflux $\left(R_{E}\right)$ of bidirectional digoxin transport across polarized MDCK-MDR1 cell monolayers.

\begin{tabular}{lcccc} 
& \multicolumn{2}{c}{ Papp $\left(\times \mathbf{1 0}^{-\mathbf{6}} \mathbf{c m ~ s}^{\mathbf{- 1}} \mathbf{)}\right.$} & & \\
\cline { 2 - 3 } & $\mathbf{A} \rightarrow \mathbf{B}$ & $\mathbf{B} \rightarrow \mathbf{A}$ & $\mathbf{R}_{\mathbf{E}}$ & Folds $\left(\mathbf{R}_{\mathbf{E}}\right)$ \\
\hline Control & $0.31 \pm 0.05$ & $11.32 \pm 0.45$ & 36.56 & \\
\hline VER $(\mu \mathrm{M})$ & & & & \\
20 & $1.32 \pm 0.14^{\star \star \star}$ & $9.42 \pm 0.50^{\star \star \star}$ & 7.14 & 5.12 \\
\hline $23-\mathrm{HBA}(\mu \mathrm{M})$ & & & & \\
0.2 & $0.40 \pm 0.07$ & $12.56 \pm 0.96$ & 31.57 & 1.16 \\
2 & $0.48 \pm 0.05^{\star}$ & $13.43 \pm 2.27$ & 27.96 & 1.31 \\
20 & $1.81 \pm 0.21^{\star \star \star}$ & $4.86 \pm 0.59^{\star \star \star}$ & 2.69 & 13.61 \\
\hline $\mathrm{BA}(\mu \mathrm{M})$ & & & & \\
0.2 & $0.37 \pm 0.09$ & $10.89 \pm 0.42$ & 29.11 & 1.26 \\
2 & $0.64 \pm 0.06$ & $10.91 \pm 0.64$ & 17.06 & 2.14 \\
20 & $0.55 \pm 0.18$ & $12.92 \pm 2.61$ & 23.42 & 1.56
\end{tabular}

Data are presented as mean $\pm S E M, n=3$. $A \rightarrow B$, apical to basal; $B \rightarrow A$, basal to apical. Net efflux was calculated as the ratio of $P_{\text {app }}$ from $B \rightarrow A$ to $A \rightarrow B$. ${ }^{*} p<0.05$, ${ }^{* *} p<0.01$, ${ }_{* * *} \mathrm{p}<0.001$ vs. control.

TABLE 2 | Apparent permeability coefficient (Papp) and net efflux $\left(R_{E}\right)$ of bidirectional VCR transport across polarized MDCK-MDR1 cell monolayers.

\begin{tabular}{|c|c|c|c|c|}
\hline & \multicolumn{2}{|c|}{ Papp $\left(\times 10^{-6} \mathrm{~cm} \mathrm{~s}^{-1}\right)$} & \multirow[b]{2}{*}{$\mathbf{R}_{\mathrm{E}}$} & \multirow[b]{2}{*}{ Folds $\left(R_{E}\right)$} \\
\hline & $A \rightarrow B$ & $\mathbf{B} \rightarrow \mathbf{A}$ & & \\
\hline Control & $0.35 \pm 0.17$ & $3.86 \pm 0.71$ & 10.89 & \\
\hline \multicolumn{5}{|c|}{ VER $(\mu \mathrm{M})$} \\
\hline 20 & $0.75 \pm 0.03^{\star}$ & $3.49 \pm 0.39$ & 4.68 & 2.33 \\
\hline \multicolumn{5}{|c|}{ 23-HBA $(\mu \mathrm{M})$} \\
\hline 0.2 & $0.69 \pm 0.30$ & $4.45 \pm 1.12$ & 6.41 & 1.70 \\
\hline 2 & $2.49 \pm 0.59^{\star \star *}$ & $0.39 \pm 0.01^{\star \star}$ & 0.16 & 70.15 \\
\hline 20 & $2.19 \pm 1.74^{\star \star}$ & $0.48 \pm 0.08^{\star}$ & 0.22 & 49.32 \\
\hline \multicolumn{5}{|l|}{$\mathrm{BA}(\mu \mathrm{M})$} \\
\hline 0.2 & $0.45 \pm 0.06$ & $3.73 \pm 0.07$ & 8.30 & 1.31 \\
\hline 2 & $0.42 \pm 0.15$ & $3.88 \pm 1.04$ & 9.18 & 1.19 \\
\hline 20 & $0.42 \pm 0.13$ & $3.83 \pm 1.01$ & 9.11 & 1.20 \\
\hline
\end{tabular}

Data are presented as mean $\pm S E M, n=3 .{ }^{*} p<0.05,{ }^{* *} p<0.01,{ }^{* * *} p<0.001$ vs. control.

\section{Inhibitory Mechanisms of BA/23-HBA on P-gp}

MDR1 shift assay was performed to confirm whether BA/23HBA could alter the P-gp conformation. The P-gp conformation-specific antibody, UIC2, was selected to predict reasonable structure change by P-gp substrates. The waves with compound treatment were shifted as compared to solvent control (Figure 6A). Additionally, fluorescence intensity showed slight increase between compound treatment and solvent which was in line with the positive control vinblastine (Figure 6B), suggesting that $\mathrm{BA} / 23-\mathrm{HBA}$ would be a substrate of P-gp with low binding affinity.

\section{Molecular Docking Mechanism Between BA/23-HBA and P-gp}

To further clarify the interaction mechanism between P-gp and BA/ 23-HBA in molecular perspective, docking simulation was performed as the method described above. BA $\left(-9.04 \mathrm{kcal} \cdot \mathrm{mol}^{-1}\right)$ docked with
TABLE 3 | Apparent permeability coefficient (Papp) and net efflux $\left(R_{E}\right)$ of bidirectional transport of 23-HBA and BA with or without verapamil across polarized MDCK-MDR1 cell monolayers.

\begin{tabular}{|c|c|c|c|c|}
\hline & \multicolumn{2}{|c|}{ Papp $\left(\times 10^{-6} \mathrm{~cm} \mathrm{~s}^{-1}\right)$} & \multirow[b]{2}{*}{$\mathbf{R}_{\mathrm{E}}$} & \multirow[b]{2}{*}{ Folds (RE) } \\
\hline & A-B & B-A & & \\
\hline \multicolumn{5}{|c|}{ 23-HBA( $\mu \mathrm{M})$} \\
\hline 0.2 & $6.73 \pm 0.09$ & $10.01 \pm 1.38$ & 1.49 & \\
\hline 2 & $7.07 \pm 0.64$ & $8.75 \pm 0.31$ & 1.24 & \\
\hline 20 & $5.95 \pm 0.94$ & $4,28 \pm 0.72$ & 0.72 & \\
\hline \multicolumn{5}{|c|}{ 23-HBA $(\mu M)+V E R$} \\
\hline 0.2 & $8.49 \pm 1.39$ & $5.20 \pm 0.59$ & $0.61^{\star \star}$ & 0.41 \\
\hline 2 & $10.03 \pm 3.22$ & $7.83 \pm 0.32$ & $0.78^{\star}$ & 0.63 \\
\hline 20 & $12.76 \pm 1.13$ & $7.47 \pm 1.64$ & 0.59 & 0.82 \\
\hline \multicolumn{5}{|c|}{$\mathrm{BA}(\mu \mathrm{M})$} \\
\hline 0.2 & $61.23 \pm 9.36$ & $55.09 \pm 9.80$ & 0.90 & \\
\hline 2 & $5.43 \pm 0.50$ & $6.51 \pm 0.81$ & 1.20 & \\
\hline 20 & $0.72 \pm 0.26$ & $0.59 \pm 0.14$ & 0.82 & \\
\hline \multicolumn{5}{|c|}{$\mathrm{BA}(\mu \mathrm{M})+\mathrm{VER}$} \\
\hline 0.2 & $104.54 \pm 10.47$ & $62.13 \pm 4.71$ & $0.59^{\star}$ & 0.66 \\
\hline 2 & $7.65 \pm 1.53$ & $6.90 \pm 0.76$ & 0.90 & 0.75 \\
\hline 20 & $0.26 \pm 0.05$ & $0.17 \pm 0.05$ & 0.64 & 0.78 \\
\hline
\end{tabular}

Data are presented as mean $\pm S E M, n=3 .{ }^{*} p<0.05,{ }^{* *} p<0.01,{ }^{* * *} p<0.001$ vs. control.

slightly higher binding energy to the structure pocket, compared to 23-HBA $\left(-8.07 \mathrm{kcal} \cdot \mathrm{mol}^{-1}\right)$. Both BA and 23-HBA could form hydrogen bonds with residues of P-gp (Figure 7). Particularly, BA could bind with SER975 and SER725 through the carboxyl on the site 28. However, 23-HBA bond with LEU 971 and SER 975 through hydroxy on the site 23. It is interesting that the binding orientation of the compounds with residues is different between BA and 23-HBA; however, the cause of this phenomenon is unknown. The results suggested that both BA and 23-HBA could show affinity with P-gp; however, the binding sites and scales were different between them.

\section{DISCUSSION}

Until now, selection of alternative drugs from natural constituents would be a reasonable choice to decrease drug resistance via P-gp and to promote cytotoxicity to cancer cells (Zhang et al., 2012; Sun et al., 2019). To investigate the role of $\mathrm{BA} / 23-\mathrm{HBA}$ to overcome $\mathrm{MDR}$, its ability to re-sensitize MCF-7/ADR cells was evaluated. Current study suggested that no cell toxicity was detected when BA or 23-HBA was used at $0-20 \mu \mathrm{M}$ as a single agent. However, combination exposure of 23-HBA $(0-20 \mu \mathrm{M})$ and ADR $(3 \mu \mathrm{M})$ showed significant cytotoxicity to MCF-7/ADR (Figure 1B), which suggested that 23-HBA could dose-dependent reduce the resistance of MCF-7/ADR cells to ADR. Inconsistently, this synergistic effect mentioned above was not observed for BA $(0-20 \mu \mathrm{M})$ and $\mathrm{ADR}(3 \mu \mathrm{M})$ (Figure 1A). As reported, MCF-7/ ADR cells were confirmed to be ADR-resistant with the mechanism such as overexpression of protein and mRNA levels of P-gp (Chen et al., 2015). Thus, 23-HBA could be a P-gp-included MDR reversal natural product, and this point was further verified by 23-HBAinduced reduction to VCR resistance in resistant MCF-7/ADR cells (Figure 2). As expected, 23-HBA, instead of BA, could enhance the ADR induced apoptosis on MCF-7/ADR cells in a concentration- 

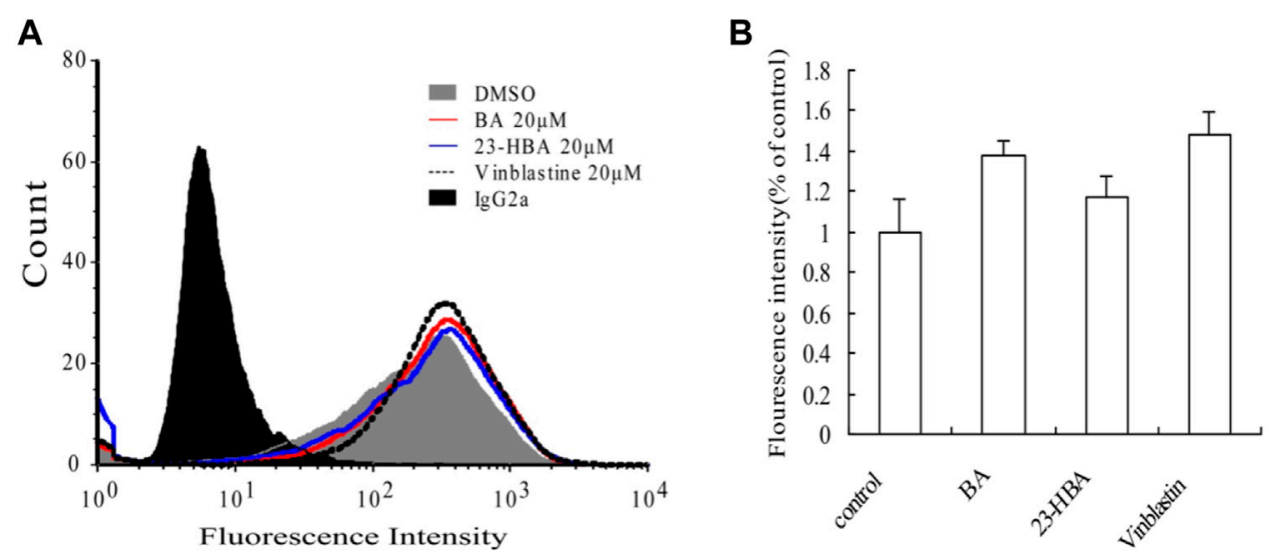

FIGURE 6 | Effects of BA and 23-HBA on the binding of conformation-sensitive antibody UIC2 to P-gp. (A), effects of compounds on the binding conditions. The cells treated with normal IgG2a were used as a background control, and DMSO treatment was selected as a solvent control. (B), results quantified from three independent experiments are presented as mean \pm SEM.
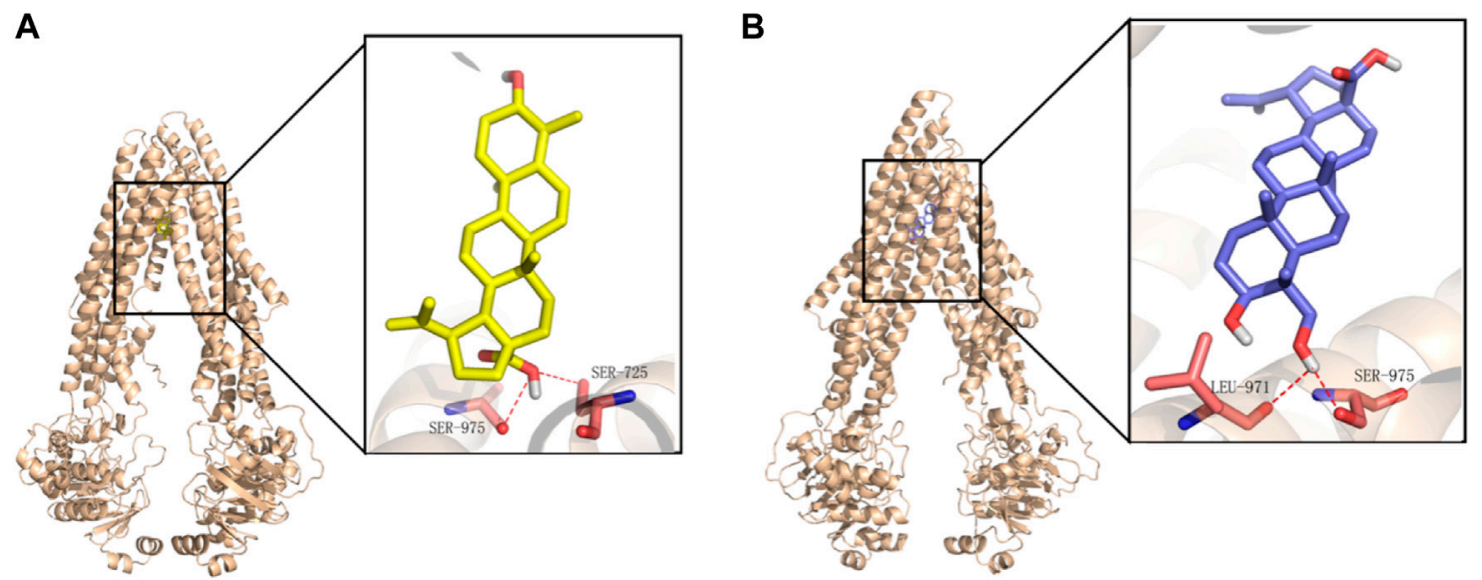

FIGURE 7 | Binding mode of BA (A) and 23-HBA (B) in the active site of P-gp. Yellow for BA, blue for 23-HBA, and magenta for binding residues of P-gp.

dependent style $(2$ and $20 \mu \mathrm{M})$ in Hoechst assay (Figure 3). However, the same effects did not appear when given 23-HBA or ADR as single agent. This further confirmed that synergistic interaction occurred when the two agents were used together.

It was interesting that BA was also confirmed to be highly related to cytotoxic activity against MDR cell lines (Jung et al., 2007; Saeed et al., 2018), whereas this does not necessarily mean that the processing was P-gp relevant. As reported, the inhibition of autocrine motility factor receptor (AMFR) activity should be the mechanism of BA to decrease MDR (Saeed et al., 2018). This could be a reasonable explication for the difference performance between BA and 23-HBA.

Indeed, previous report also suggested that 23-HBA could synergize the antitumor activity of ADR in multiple approaches (Zheng et al,, 2010). However, the protein expression of P-gp was not modulated by 23-HBA during this process. Until now, the molecular mechanisms related to P-gp that underlie these processes remained unclear. To further explore the mechanism, intracellular accumulation was taken by measuring the transport of ADR and VCR in MCF-7/ADR or MCF-7/S cell lines (Figure 4). Similar to P-gp positive inhibitor verapamil, current study revealed that the intracellular accumulation of ADR and VCR, both P-gp substrates, were significantly promoted in MCF-7/ADR cells incubated with 23-HBA $(0.2-20 \mu \mathrm{M})$ (Figures 4A,C); however, 23HBA showed minor effect on the MCF-7/S cells (Figures 4B,D). These points are in line with the demonstrated effect of 23-HBA on MDR, suggesting that 23-HBA could change P-gp activity and transport to increase the intracellular accumulation of drugs.

In this study, the interaction mechanism between BA/23-HBA and P-gp was firstly investigated by multiple in vitro and in silico approaches. Both Caco-2 and MDCK-MDR1 cell models were firstly used to investigate the interaction between BA/23-HBA and P-gp. The active transport of VCR, known P-gp substrate, could be inhibited by $23-\mathrm{HBA}$ instead of BA (Table 2). The results could reasonably explain why the MDR could be reversed by 23-HBA, but not BA (Figure 1). Furthermore, the weak inhibition of BA/23-HBA by VER in MDCK-MDR1 cells suggested both compounds are not a potent substrate of P-gp (Table 3), which was further confirmed by MDR1 shift approach (Figure 6). In molecular docking study could give the reason that the affinity of 23-HBA and BA with $\mathrm{P}$-gp was 
different. The docking results indicated that amino acid residues in P-gp that interact with BA and 23-HBA were inconsistent (Figure 7). In addition, the combination mode and energy were also different. This further confirmed that the different pharmacokinetics and pharmacodynamics related with P-gp for the two compounds.

In conclusion, this in vitro study provides prospects that 23HBA would greatly promote the efficiency of chemotherapeutic agent in P-gp resistant MDR cells. Furthermore, overcoming of MDR by 23-HBA was suggested to be related with P-gp inhibition. The in vitro and in silico study further revealed that 23-HBA and BA showed different interaction mechanisms with P-gp. Evidence of MDR reversal by 23-HBA would confirm the synergetic benefits of combining the product with other conventional anti-tumor agents in overcoming drug resistance in cancer chemotherapy.

\section{DATA AVAILABILITY STATEMENT}

The original contributions presented in the study are included in the article/Supplementary Material, and further inquiries can be directed to the corresponding authors.

\section{REFERENCES}

Alfarouk, K. O., Stock, C. M., Taylor, S., Walsh, M., Muddathir, A. K., Verduzco, D., et al. (2015). Resistance to Cancer Chemotherapy: Failure in Drug Response from ADME to P-Gp. Cancer Cel Int 15, 71. doi:10.1186/S12935-015-0221-1

Chen, T., Wang, C., Liu, Q., Meng, Q., Sun, H., Huo, X., et al. (2015). Dasatinib Reverses the Multidrug Resistance of Breast Cancer MCF-7 Cells to Doxorubicin by Downregulating P-Gp Expression via Inhibiting the Activation of ERK Signaling Pathway. Cancer Biol. Ther. 16, 106-114. doi:10.4161/15384047.2014.987062

Dewanjee, S., Dua, T. K., Bhattacharjee, N., Das, A., Gangopadhyay, M., Khanra, R., et al. (2017). Molecules Natural Products as Alternative Choices for P-Glycoprotein (P-Gp) Inhibition. Molecules 22, 871. doi:10.3390/ molecules22060871

Fong, H. H. S., Kinghorn, A. D., Brown, D. M., and Wani, M. C. (1995). Discovery of Betulinic Acid as a Selective Inhibitor of Human Melanoma that Functions by Induction of Apoptosis. Nat. Med. 1, 2-7. doi:10.1038/nm1095-1046

Fulda, S. (2008). Betulinic Acid for Cancer Treatment and Prevention. Int. J. Mol. Sci. 9, 1096. doi:10.3390/IJMS9061096

Fulda, S., and Kroemer, G. (2009). Targeting mitochondrial apoptosis by betulinic acid in human cancers. Drug Discov. Today 14, 885-890. doi:10.1016/ J.DRUDIS.2009.05.015

Jia, Y., Liu, Z., Wang, C., Meng, Q., Huo, X., Liu, Q., et al. (2016). P-gp, MRP2 and OAT1/OAT3 Mediate the Drug-Drug Interaction between Resveratrol and Methotrexate. Toxicol. Appl. Pharmacol. 306, 27-35. doi:10.1016/ J.TAAP.2016.06.030

Jung, G. R., Kim, K. J., Choi, C. H., Lee, T. B., Han, S. I., Han, H. K., et al. (2007). Effect of Betulinic Acid on Anticancer Drug-Resistant colon Cancer Cells. Basic Clin. Pharmacol. Toxicol. 101, 277-285. doi:10.1111/j.1742-7843.2007.00115.x

Li, X., Hu, J., Wang, B., Sheng, L., Liu, Z., Yang, S., et al. (2014). Inhibitory Effects of Herbal Constituents on P-Glycoprotein In Vitro and In Vivo: Herb-Drug Interactions Mediated via P-Gp. Toxicol. Appl. Pharmacol. 275, 163-175. doi:10.1016/J.TAAP.2013.12.015

Liu, Z., and Liu, K. (2016). Application of Model-Based Approaches to Evaluate Hepatic Transporter-Mediated Drug Clearance: In Vitro, In Vivo, and In Vitro-In Vivo Extrapolation. Curr. Drug Metab. 17(5): 456-68. doi:10.2174/1389200217666160111124139

Liu, Z., Mi, J., Yang, S., Zhao, M., Li, Y., and Sheng, L. (2016). Effects of P-Glycoprotein on the Intestine and Blood-Brain Barrier Transport of

\section{AUTHOR CONTRIBUTIONS}

ZL-Data analysis, Writing-review and editing; XWMethodology, Data analysis; GW-Supervision, Project administration; YZ-Funding acquisition, Project administration, Review, and editing.

\section{FUNDING}

This work was supported by National Natural Science Foundation of China (No. 81903724), and grant from Natural Science Foundation of Jiangxi Province (No. 20181BBG70008).

\section{SUPPLEMENTARY MATERIAL}

The Supplementary Material for this article can be found online at: https://www.frontiersin.org/articles/10.3389/fphar.2021.796745/ full\#supplementary-material

YZG-331, a Promising Sedative-Hypnotic Compound. Eur. J. Pharmacol. 791:339-347. doi:10.1016/j.ejphar.2016.08.039

Liu, Z., Wang, C., Liu, Q., Meng, Q., Cang, J., Mei, L., et al. (2011). Uptake, Transport and Regulation of JBP485 by PEPT1 In Vitro and In Vivo. Peptides 32(4):747-54. doi:10.1016/j.peptides.2011.01.019

Maino, D. M., Tran, S., and Mehta, F. (2000). Side Effects of Chemotherapeutic Oculo-Toxic Agents: a Review. Clin. Eye Vis. Care 12, 113-117. doi:10.1016/ S0953-4431(00)00053-9

Masoudkabir, F., Sarrafzadegan, N., Gotay, C., Ignaszewski, A., Krahn, A. D., Davis, M. K., et al. (2017). Cardiovascular Disease and Cancer: Evidence for Shared Disease Pathways and Pharmacologic Prevention. Atherosclerosis 263, 343-351. doi:10.1016/J.ATHEROSCLEROSIS.2017.06.001

Munteanu, E., Verdier, M., Grandjean-Forestier, F., Stenger, C., Jayat-Vignoles, C., Huet, S., et al. (2006). Mitochondrial Localization and Activity of P-Glycoprotein in Doxorubicin-Resistant K562 Cells. Biochem. Pharmacol. 71, 1162-1174. doi:10.1016/J.BCP.2006.01.006

Nanayakkara, A. K., Follit, C. A., Chen, G., Williams, N. S., Vogel, P. D., and Wise, J. G. (2018). Targeted Inhibitors of P-Glycoprotein Increase ChemotherapeuticInduced Mortality of Multidrug Resistant Tumor Cells OPEN. Sci Rep 8(1):967. doi:10.1038/s41598-018-19325-x

Saeed, M. E. M., Mahmoud, N., Sugimoto, Y., Efferth, T., and Abdel-Aziz, H. (2018). Betulinic Acid Exerts Cytotoxic Activity against Multidrug-Resistant Tumor Cells via Targeting Autocrine Motility Factor Receptor (AMFR). Front. Pharmacol. 9. doi:10.3389/fphar.2018.00481

Shi, R., Li, W., Zhang, X., Zhang, Y., Peng, H., Xie, Y., et al. (2011). A Novel Indirubin Derivative PHII-7 Potentiates Adriamycin Cytotoxicity via Inhibiting P-Glycoprotein Expression in Human Breast Cancer MCF-7/ADR Cells. Eur. J. Pharmacol. 669, 38-44. doi:10.1016/J.EJPHAR.2011.07.047

Simone, F. (2009). Targeting Mitochondrial Apoptosis by Betulinic Acid in Human Cancers. Drug Discov. Today 14, 885-890. doi:10.1016/J.DRUDIS.2009.05.015

Sun, H., and Pang, K. S. (2008). Permeability, Transport, and Metabolism of Solutes in Caco-2 Cell Monolayers: A Theoretical Study. Drug Metab. Dispos 36, 102-23. doi:10.1124/dmd.107.015321

Sun, Y., Liu, W., Wang, C., Meng, Q., Liu, Z., Huo, X., et al. (2019). Combination of Dihydromyricetin and Ondansetron Strengthens Antiproliferative Efficiency of Adriamycin in K562/ADR through Downregulation of SORCIN: A New Strategy of Inhibiting P-Glycoprotein. J. Cel. Physiol. 234, 3685-3696. doi:10.1002/JCP.27141

Wang, L., Wang, C., Jia, Y., Liu, Z., Shu, X., and Liu, K. (2016). Resveratrol Increases Anti-proliferative Activity of Bestatin through Downregulating P-Glycoprotein 
Expression via Inhibiting PI3K/Akt/mTOR Pathway in K562/ADR Cells. J. Cel. Biochem. 117, 1233-1239. doi:10.1002/JCB.25407

Xue, C., Wang, C., Liu, Q., Meng, Q., Sun, H., Huo, X., et al. (2016). Targeting P-Glycoprotein Expression and Cancer Cell Energy Metabolism: Combination of Metformin and 2-deoxyglucose Reverses the Multidrug Resistance of K562/Dox Cells to Doxorubicin. Tumor Biol. 377 (37), 8587-8597. doi:10.1007/S13277-015-4478-8

Zarros, A., Ye, Y., John, D., Lane, R., Salomone, S., Falzone, L., et al. (2018). Evolution of Cancer Pharmacological Treatments at the Turn of the Third Millennium. Front. Pharmacol. 9, 1300. doi:10.3389/fphar.2018.01300

Zhang, D. M., Shu, C., Chen, J. J., Sodani, K., Wang, J., Bhatnagar, J., et al. (2012). BBA, a Derivative of 23-hydroxybetulinic Acid, Potently Reverses ABCB1-Mediated Drug Resistance In Vitro and In Vivo. Mol. Pharm. 9, 3147-3159. doi:10.1021/mp300249s

Zhang, J., Zhou, F., Wu, X., Gu, Y., Ai, H., Zheng, Y., et al. (2010). 20(S)-ginsenoside Rh2 Noncompetitively Inhibits P-Glycoprotein In Vitro and In Vivo: A Case for HerbDrug Interactions. Drug Metab. Dispos. 38, 2179-2187. doi:10.1124/dmd.110.034793

Zhang, Y., Wang, C. Y., Duan, Y. J., Huo, X. K., Meng, Q., Liu, Z. H., et al. (2018). Afatinib Decreases P-Glycoprotein Expression to Promote Adriamycin Toxicity of A549T Cells. J. Cel. Biochem. 119, 414-423. doi:10.1002/JCB.26194

Zheng, Y., Zhou, F., Wu, X., Wen, X., Li, Y., Yan, B., et al. (2010). 23Hydroxybetulinic Acid from Pulsatilla Chinensis (Bunge) Regel Synergizes the Antitumor Activities of Doxorubicin In Vitro and In Vivo. J. Ethnopharmacol. 128, 615-622. doi:10.1016/j.jep.2010.02.004
Zhou, Y., Wen, J., and Wang, G. (2019). Identification of Cytochrome P450 Isoenzymes Involved in the Metabolism of 23-hydroxybetulinic Acid in Human Liver Microsomes. Pharm. Biol. 58, 60-63. doi:10.1080/ 13880209.2019.1701500

Conflict of Interest: The authors declare that the research was conducted in the absence of any commercial or financial relationships that could be construed as a potential conflict of interest.

Publisher's Note: All claims expressed in this article are solely those of the authors and do not necessarily represent those of their affiliated organizations, or those of the publisher, the editors, and the reviewers. Any product that may be evaluated in this article, or claim that may be made by its manufacturer, is not guaranteed or endorsed by the publisher.

Copyright $\odot 2021 \mathrm{Liu}$, Wen, Wang and Zhou. This is an open-access article distributed under the terms of the Creative Commons Attribution License (CC $B Y)$. The use, distribution or reproduction in other forums is permitted, provided the original author(s) and the copyright owner(s) are credited and that the original publication in this journal is cited, in accordance with accepted academic practice. No use, distribution or reproduction is permitted which does not comply with these terms. 